\title{
En búsqueda de la pared perfecta. Decisiones que evitan la desaparición de arte urbano
}

Andrea Fernández Arcos | Escuela Superior de Conservación y Restauración de Bienes Culturales de Galicia

URL de la contribución <www.iaph.es/revistaph/index.php/revistaph/article/view/4872>

A aquellos elementos que se etiquetan bajo la denominación de patrimonio cultural, las comunidades que los valoran de tal modo les desean una cierta garantía de permanencia. Pero cuando se pinta una obra de arte en la calle, sobre muros o fachadas, la pintura queda expuesta a multitud de factores que muy difícilmente serán controlables.

En muchas ocasiones esto es motivo de preocupación para quienes las han creado y también para aquellas personas o instituciones encargadas de su custodia, cuando lo que se pretende es su conservación, al menos a medio plazo. Agentes climáticos, vandalismo o contaminación, son algunos de los factores que, en mayor o menor medida, incidirán día a día sobre la obra acortando su vida de forma paulatina.

Pero existen una serie de agentes que sí es posible tener en cuenta en los estadios anteriores a la ejecución de la pintura, como la selección de unos materiales estables, la elaboración de la obra con una técnica cuidada, o la selección y preparación del soporte, cuestiones que normalmente dependen de los creadores.

La mayor parte de estas decisiones están sujetas a que la obra esté "autorizada", puesto que la celeridad que requiere pintar de forma más o menos espontánea en lugares no consentidos, y la ausencia de patrocinio y licencias que va ligada a estas acciones improvisadas, limita mucho el abanico de decisiones que están relacionadas con los factores que facilitarán la conservación de la pieza.

Es decir, para una obra de arte urbano ilegal o alegal difícilmente se podrá elegir y preparar previamente el soporte, de cara a una mejor conservación, o elegir una

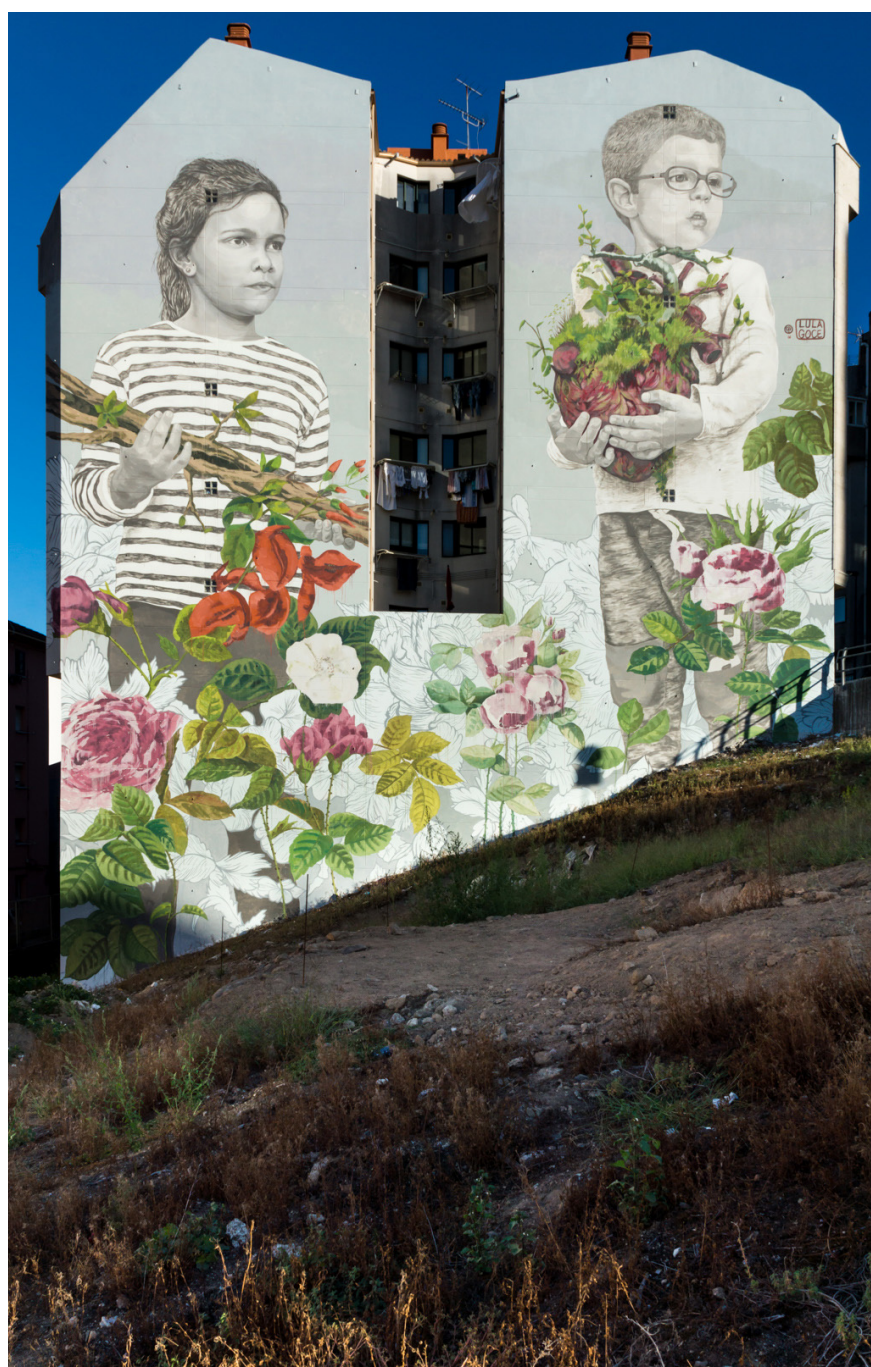

Los niños que miran al horizonte, mural de Lula Goce | foto r2hox

superficie que sea difícilmente vandalizable, o incluso evaluar el entorno para verificar que la obra dispondrá de una cierta amplitud de mirada que facilite su disfrute y promueva su aprecio. 


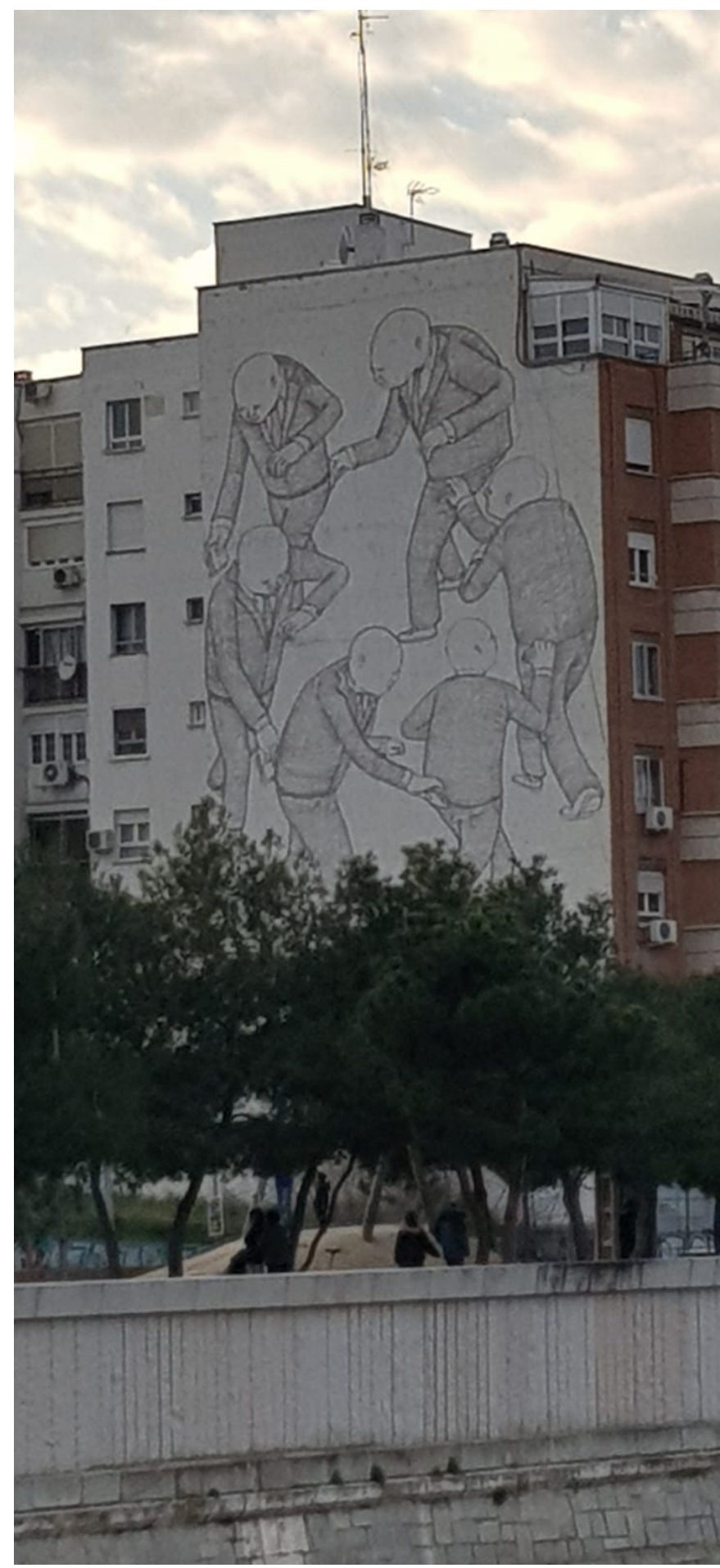

Mural desaparecido en Usera (Madrid) del artista Blu | foto Lucía Miragaya
Estas determinaciones son, sin embargo, mucho más fáciles de tomar en el campo del muralismo urbano, en donde se asigna una superficie, normalmente bajo el amparo institucional, para que los artistas puedan crear sus encargos.

Efectivamente, en este ámbito del arte urbano las decisiones proceden, más que de los artistas, de las entidades que promueven las creaciones, que son quienes habitualmente realizan la selección de la pared. Sin embargo, el esfuerzo de los artistas puede desaparecer inesperadamente a causa de reformas en el edificio, como ha ocurrido con el mural del artista boloñés Blu en Madrid, o sepultado por una nueva construcción, como sucederá con los niños que miran al horizonte en Vigo, pintados por Lula Goce. Por ello, es necesario conocer las previsiones sobre el edificio, y los proyectos de desarrollo urbanístico que puedan afectar a las paredes que interesan.

Cuando la creación de un mural altera otros valores del bien sobre el que se pinta, por el mero hecho de alterar la apariencia de la superficie, es posible que derive en una crítica que pueda afectar a la permanencia de la pintura, como ha ocurrido en el Faro de Ajo en Cantabria, pintado con llamativos colores por Okuda. En este caso, por decisión de la Autoridad Portuaria de Santander, el mural será borrado en, a lo sumo, 8 años, mientras que, en paralelo, la fiscalía estudiará la posibilidad de que se hayan producido daños al patrimonio. Otro ejemplo sería el de la intervención en la iglesia de San Rosendo de Ferrol, en la que se pintó un mural con ocasión de la última edición del Festival de las Meninas de Canido, lo que motivó que la Asociación Ferrolterra Antiga dirigiese un escrito de queja a la administración local por considerar inapropiada esta acción sobre una construcción de esta tipología.

Si lo que se busca, por tanto, es la permanencia de la obra y evitar su pérdida drástica, es necesario que exista una cierta garantía de trabajar sobre una pared en la que, al pintar la superficie, no se vean perjudicados otros valores. 


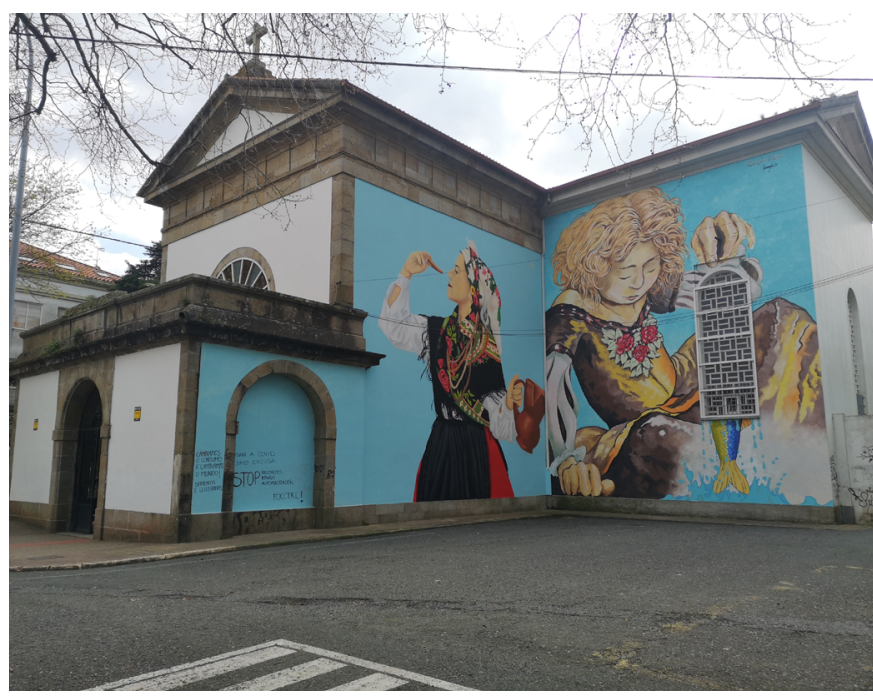

Mural de Álex Fernández y Gonzalo Alonso en la iglesia de San Rosendo de Ferrol (A Coruña) | foto Andrea Fernández

Obviamente, algunas de estas previsiones pueden cambiar con el paso del tiempo una vez la obra ha sido pintada, como ha sucedido en Barcelona con el icónico mural de la fachada de La Carbonería, que fue eliminado en verano de 2020 tras asignarle al edificio un nivel de protección C (bien de interés urbanístico), lo que implicaba restituir el aspecto original de este inmueble construido a mediados del s. XIX.

\section{Conclusión}

Todas las decisiones anteriores al comienzo de la aplicación de la pintura que pretenden alargar la vida de las obras, como la selección de la pared que será pintada, encorsetan en alguna medida la creación, limitando el abanico de posibilidades al alcance de los creadores. Las decisiones que inclinan la balanza en favor de la conservación o de la libertad de creación deberán tomarse teniendo presente la opinión de los artistas interesados. Por otra parte, la exigente previsión que implica la toma de estas decisiones limitará la aplicación de estas medidas preventivas al arte urbano autorizado.

\section{BIBLIOGRAFÍA}

- Asociación Cultural Ferrolterra Antiga (2020) Carta ao Concello: sobre a intervención artística na capela da igrexa de San Rosendo de Ferrol. Ferrolterra Antiga, 8 de septiembre de 2020. Disponible en: https://ferrolterraantiga.blogspot. com/2020/09/carta-ao-concello-sobre-intervencion.html [Consulta: 07/03/2021]

- García Gayo, E. (2016) Etapas del Arte Urbano. Aportaciones para un protocolo de conservación. Ge-Conservación, vol. 10, pp. 97-108. Disponible en: https://www.ge-iic.com/ojs/index. php/revista/article/view/401 [Consulta: 01/03/2021]

- La Fiscalía investigará la intervención de Okuda en el faro Ajo tras la denuncia de Izquierda Unida (2020) El Diario Montañés, 8 de septiembre de 2020. Disponible en: https:// www.eldiariomontanes.es/cantabria/fiscalia-investigaraintervencion-20200908212516-nt.html [Consulta: 12/03/2021]

- López, H. (2020) Barcelona borra el gran mural de La Carbonería, icono del arte callejero. El periódico, 1 de julio de 2020. Disponible en: https://www.elperiodico.com/es/ barcelona/20200701/bcn-borra-mural-carboneria-arte-urbanografiti-okupas-8020134 [Consulta: 10/03/2021] 